\title{
Faster the better: a reliable technique to sample anopluran lice in large hosts
}

\author{
María Soledad Leonardi
}

Received: 22 November 2013 / Accepted: 10 January 2014 / Published online: 22 April 2014

(C) Springer-Verlag Berlin Heidelberg 2014

\begin{abstract}
Among Anoplura, the family Echinophthiriidae includes those species that infest mainly the pinnipeds. Working with large hosts implies methodological considerations as the time spent in the sampling, and the way in that the animal is restrained. Previous works on echinophthiriids combined a diverse array of analyses including field counts of lice and in vitro observations. To collect lice, the authors used forceps, and each louse was collected individually. This implied a long manipulation time, i.e., $\approx 60 \mathrm{~min}$ and the need to physically and/or chemically immobilize the animal. The present work described and discussed for the first a sample technique that minimized the manipulation time and also avoiding the use of anesthesia. This methodology implied combing the host's pelage with a fine-tooth plastic comb, as used in the treatment of human pediculosis, and keeping the comb with the lice retained in a Ziploc $^{\circledR}$ bag with ethanol. This technique was used successfully in studies of population dynamic, habitat selection, and transmission pattern, being a reliable methodology. Lice are collected entirely and are in a good condition to prepare them for mounting for studying under light or scanning electron microscopy. Moreover, the use of the plastic comb protects from damaging taxonomically important structures as spines being also recommended to reach taxonomic or morphological goals.
\end{abstract}

Keywords Anoplura $\cdot$ Echinophthiriidae $\cdot$ Pinnipeds · Sampling $\cdot$ Technique

M. S. Leonardi $(\square)$

Laboratorio de Parasitología, Centro Nacional Patagónico,

CENPAT-CONICET, Boulevard Brown 2915, PC U9120ACV,

Puerto Madryn, Argentina

e-mail: leonardi@cenpat.edu.ar

\section{Introduction}

The family Echinophthiriidae (Anoplura: Phthiraptera) includes those species of lice infecting the pinnipeds (Durden and Musser 1994), a mammalian group that includes fur seals and sea lions (Otariidae), walruses (Odobenidae), and true seals (Phocidae). Because of their large size and potential danger, manipulation of pinnipeds requires specialized handling and research techniques (Gales et al. 2006). Moreover, fieldwork with these animals implied ethical and scientific responsibilities that are reflected in a trade-off between the effect of the study on the animals and the value of the results obtained (Halliday 1995; Powell and Proulx 2003).

Previous works on echinophthiriids combined a diverse array of analyses including field counts of lice and in vitro observations. Field counts of lice on a single occasion can convey only a static picture of population dynamics, and the follow-up of infections on single, or few caged, or restrained hosts (Murray and Nicholls 1965; Kim 1975) may have a limited value to infer population patterns. To collect lice, the authors used forceps, and each louse was collected individually. This implied a long manipulation time, i.e., $\approx 60 \mathrm{~min}$ for the need to physically and/or chemically immobilize the animal.

The main objective of the present work is to formally describe a method for quantifying lice, reducing the manipulation time, and improving the results obtained. The described technique is compared with the results obtained from the methodology previously reported on pinnipeds for collecting and quantifying echinophthiriids.

\section{Materials and methods}

Data were obtained from Leonardi (2007) and Leonardi (2014). Those studies were carried out throughout four consecutive 
years (2005-2008) in the sea lion rookery of Punta León, Chubut Province, Argentina ( $\left.43^{\circ} 04^{\prime} \mathrm{S}, 64^{\circ} 29^{\prime} \mathrm{W}\right)$. To collect lice, each pup was restrained by two people while a third person (the same one in all collections to minimize biases) combed the pelage with fine-tooth combs of the type used for treating human pediculosis (Fig. 1). During the survey of 2005-2006, retained lice were collect with forceps and stored in plastic Eppendorf tubes with $96 \%(v / v)$ ethanol (Leonardi 2007). In the season of 2007-2008, it was also used a comb but the entire comb was put in a Ziploc ${ }^{\circledR}$ bag with ethanol (Leonardi 2013). Lice were classified into nymphal stages, and male and female adults following Leonardi et al. (2009). Infestation parameters were estimated following Bush et al. (1997) and Rósza et al. (2000) and were obtained with the free software Quantitative Parasitology v.3 (Reiczigel and Rózsa 2005). Statistical significance was set at $p<0.05$. Nonparametric tests, as described by Zar (1994), were used because in each case both normality and homoscedasticity were rejected even on log-transformed data. To test differences in abundance, it was performed a Mann-Whitney test. Moreover, to test the efficacy of the technique, it was particularly analyzed the prevalence and abundance of nymphs 1 , the smallest and the most difficult to collect stage.

\section{Results}

Overall, 231 South American sea lion pups were included in this study ( $n=52$ in 2005, $n=43$ in 2006, $n=73$ in 2007, and $n=63$ in 2008). Prevalence and mean intensity of Antarctophthirus microchir are summarized for each year in Table 1.

No significant differences were observed between years, i.e., 2005 versus 2006 and 2007 versus 2008, where the same methodology was used for either prevalence or mean intensity $\left(\chi^{2}=0.014, \mathrm{df}=1, p=0.905\right.$; Mann-Whitney test, $\mathrm{Z}=-1.545$, $p=0.122$, respectively, for 2005 vs. 2006 ; and $\chi^{2}=2.407$, $\mathrm{df}=1, p=0.121$; Mann-Whitney test, $Z=-0.323, p=0.747$, respectively, for 2007 vs. 2008) (Table 1); therefore, both years for each methodology employed were considered together for subsequent analyses. Prevalence did not differ between years (Fisher's exact test, $p=0.172$ ). However, differences were significant among years when mean intensity (Mood's median test, $p=0.000$; Fig. 2 ) and abundance (Kruskal-Wallis test, $\chi^{2}=33.349, \mathrm{df}=3, p=0.000$ ) were compared.

Moreover, when it was considered, only the results of nymph 1 reflected significant differences in prevalence (Fisher's exact test, $p=0.000$ ), median intensity (Mood's median test, $p=0.000$; Fig. 3), and abundance (Kruska-Wallis test, $X^{2}=48.666, \mathrm{df}=3, p=0.000$ ).

\section{Discussion}

Previous studies on echinophthiriids have benefited from long periods (e.g., 45-60 min) of examination of wild pups or dead, captive, or restrained adult seals (Murray and Nicholls 1965; Murray et al. 1965; Kim 1972, 1975). However, using the described technique, the handling time of pups was very short, i.e., less than $5 \mathrm{~min}$. Manipulation time is not a minor issue. Researchers working with wildlife have ethical and scientific responsibilities to minimize the adverse effects they could have on the study animals, while maximizing the value of the research (Halliday 1995; Powell and Proulx 2003).

Pinnipeds are large species that can put the researchers in danger, so physical and/or chemical immobilization is generally required (Laws 1993). Although physical restraint can be more dangerous to the researcher, it is usually inexpensive. Physical restraint alone has been used successfully for many pinniped species (Rand 1950; Laws 1993). Chemical immobilization of pinnipeds is costly and time consuming, and can have unpredictable results (Stirling 1966). The efficacy of immobilizing drugs may vary according to species, age, sex,
Fig. 1 Left, detail of the fieldwork during lice sampling. Right, photograph of the louse Antarctophthirus microchir from South American sea lion

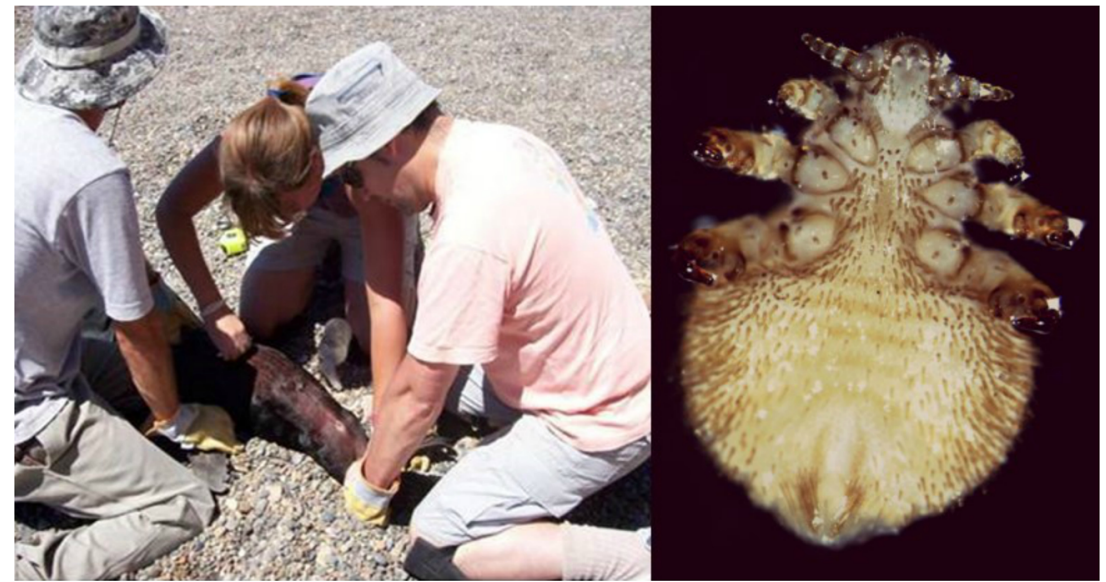


Table 1 Infection parameters for the louse Antarctophthirus microchir from South American sea lions, considering the sampling technique used each year

\begin{tabular}{|c|c|c|c|c|c|}
\hline & Technique & $n$ & Prevalence $(\%)$ & Mean intensity & Mean abundance \\
\hline 2005 & Combing and forceps & 52 & 84.6 & 17.682 & 14.962 \\
\hline 2006 & & 43 & 83.7 & 14.417 & 12.070 \\
\hline 2007 & Combing and Ziploc@ bag & 73 & 87.7 & 68.422 & 59.986 \\
\hline 2008 & & 63 & 95.2 & 59.550 & 56.714 \\
\hline
\end{tabular}

time of year, and weather conditions (Laws 1993). As a general rule, sedation or anesthetic should only be considered if it reduces the risk of the restraint of the animal (Gales et al. 2009). Furthermore, even working with the easily handled pups, the restraint should be very brief. The technique to immobilize them implied restrained by their neck and this should compromise breathing (Gales et al. 2009).

Combing of pelage was used as an alternative technique to obtain abundance indices with a good accuracy. The use of a fine-tooth comb minimizes differential sampling of developmental stages. The comb inter-teeth width is narrow enough $(300 \mu \mathrm{m})$ to retain all the stages (mean length and width of the smallest nymphal instars are 980 and $450 \mu \mathrm{m}$, respectively, and mean egg length is $930 \mu \mathrm{m}$ Leonardi et al. 2009).

In a recent paper, Gallardo et al. (2013) compared the efficacy of different commercial combs in removing different instars of Pediculus humanus capitis. They found differences, being metal combs are more effective than plastic ones. The comparison of the same material combs suggested that the space between comb teeth is an important feature in removing lice. The most effective plastic comb has smaller distance between their teeth $(0.23$ vs. $0.3 \mathrm{~mm})$. Combing was reliable in sampling echinophthiriids lice because inter-teeth width of combs was narrow enough $(300 \mu \mathrm{m})$ to minimize differential sampling of developmental stages (mean length and width of the smallest nymphal instars are 980 and $450 \mu \mathrm{m}$,

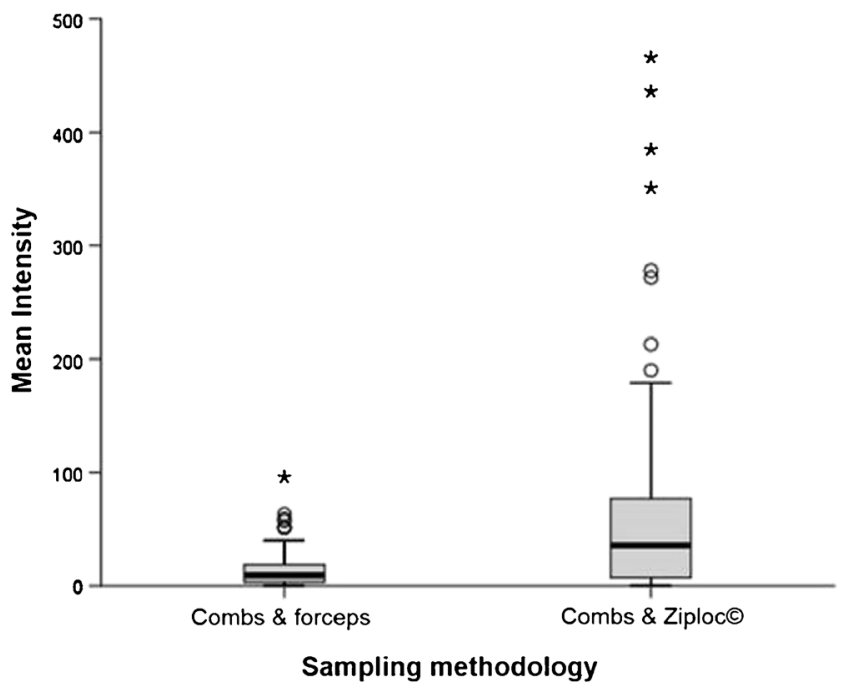

Fig. 2 Mean intensity ( \pm SD) of Antarctophthirus microchir in South American sea lions considering the sample technique used, i.e., comb and forceps or comb and Ziploc ${ }^{\mathbb{R}}$ respectively; see Leonardi et al. 2009). Gallardo et al. (2013) also demonstrated that metal combs were more effective than plastic combs in removing mobile stages and eggs. However, in order to preserve lice to studies related with morphology or to keep them alive, metal comb is not used since it could damage the individuals.

The described methodology has proven useful to study population dynamics (Aznar et al. 2009), habitat selection (Leonardi et al. 2012a), and transmission patterns (Leonardi et al. 2013). This technique is also recommended to reach taxonomic or morphological goals. Lice are collected entirely and are in a good condition to prepare them for mounting for studying under light or scanning electron microscopy (SEM) (Leonardi et al. 2009, 2012b). The use of the plastic comb protects from damaging taxonomically important structures as spines that are apparently used to fix a layer of host's sebum that offers protection against low water temperatures (Mehlhorn et al. 2002), and scales that are postulated to function as a plastron that traps bubbles of air during immersions (Mehlhorn et al. 2002; Leonardi et al. 2012b).

The principal disadvantage of this technique is that when the analyzed hosts are pups, it misses the head. As mentioned before, the restrain of the pup is by their neck expose the risk of bites. Therefore, it is recommendable to add a visual search of the head. However, as reported by Clayton and Drown (2001), this procedure reduces standardization and efficiency.

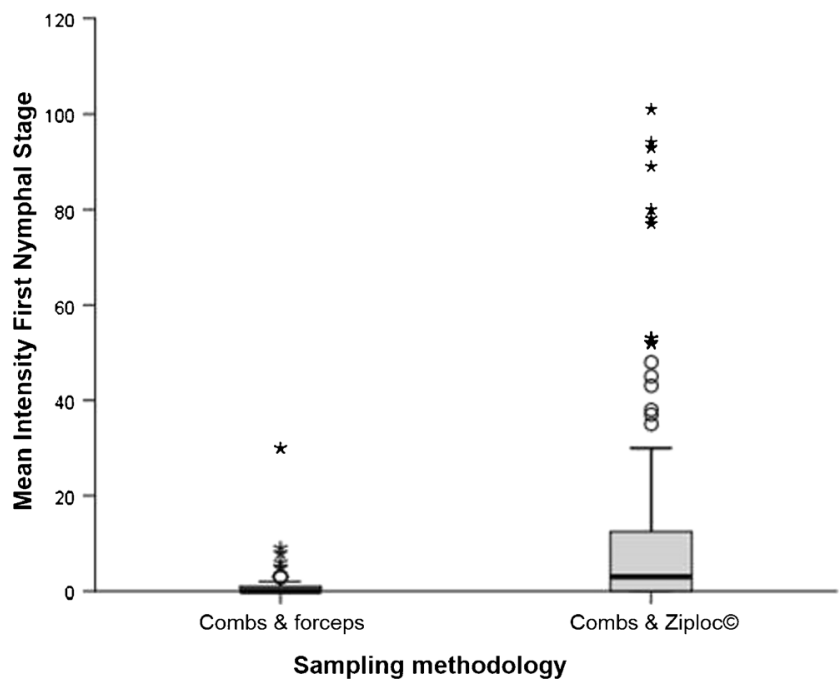

Fig. 3 Mean intensity ( \pm SD) of first nymphal stage of Antarctophthirus microchir in South American sea lions considering the sample technique used, i.e., comb and forceps or comb and Ziploc ${ }^{\circledR}$ 
It would depend on the objectives of each particular study and/ or host-parasite system to determine the relative importance of this area.

Acknowledgments The author thanks D. Vales, M. Feijoo, M. Degrati, N.A. García, G. Giardino, M.F. Grandi, M.J. Klaich, A. Mandiola, and L. Silva for their invaluable assistance in the fieldwork. Institutional and logistic support was given by Centro Nacional Patagónico (CONICET, Argentina) under permits of the Secretaría de Áreas Protegidas y Turismo and the Dirección de Fauna y Flora Silvestre, Chubut Province (Argentina). For comments on earlier versions of the manuscript, the author is grateful to Carlos Rumbold and Dr. Cynthia Awruch. Thanks are given to the Ministerio de Ciencia, Tecnología e Innovación Productiva de la Nación for the promotion of the scientific Argentinean program and the support to public education.

\section{References}

Aznar FJ, Leonardi MS, Berón-Vera B, Vales DG, Ameghino S, Raga JA, Crespo EA (2009) Population dynamics of Antarctophthirus microchir (Anoplura: Echinophthiriidae) in pups from South American sea lion, Otaria flavescens, in Northern Patagonia. Parasitology 136:293-303

Bush AO, Lafferty KD, Lotz JM, Shostak AW (1997) Parasitology meets ecology on its own terms: Margolis et al. revisited. J Parasitol 83: 575-583

Clayton DH, Drown DM (2001) Critical evaluation of five methods for quantifying chewing lice (Insecta: Phthiraptera). J Parasitol 87: 1291-1300

Durden LA, Musser GG (1994) The sucking lice (Insecta, Anoplura) of the world: a taxonomic checklist with records of mammalian hosts and geographical distributions. Bull Am Mus Nat Hist 218:1-90

Gales N, Brennan A, Baker R (2006) Ethics and marine mammal research. In: Marine mammals: fisheries, tourism and management issues. In: Gales N, Hindell M, Kirkwood R (Eds) CSIRO Publishing, pp 321-329

Gales N, Bowen WD, Johnston DW, Kovacs KM, Littnan CL, Perrin WF, Reynolds JE III, Thompson PM (2009) Guidelines for the treatment of marine mammals in field research. Mar Mammal Sci 25:725-736

Gallardo A, Toloza A, Vassena C, Picollo MI, Mougabure-Cueto G (2013) Comparative efficacy of commercial combs in removing head lice (Pediculus humanus capitis) (Phthiraptera: Pediculidae). Parasitol Res 112:1363-1366

Halliday T (1995) More on toe-clipping. Froglog 12:3

Kim KC (1972) Louse populations of the northern fur seal (Callorhinus ursinus). Am J Vet Res 33:2027-2036

Kim KC (1975) Ecology and morphological adaptation of the sucking lice (Anoplura, Echinophthiriidae) on the northern fur seal. Rapp PV Réun Cons Int Explor Mer 169:504-515
Laws RM (1993) Development of technology and research needs. In: Laws RM (ed) Antarctic seals: Research methods and techniques. Cambridge University Press, Cambridge

Leonardi MS (2007) Dinámica poblacional de Antarctophthirus microchir (Anoplura, Echinophthiriidae) en crías de lobo marino de un pelo, en el norte de Patagonia. Argentina. Degree thesis. Universidad Nacional de Mar del Plata, Argentina

Leonardi MS (2014) Coadaptación entre Antarctophthirus microchir (Anoplura: Echinophthiriidae) y el lobo marino de un pelo (Otaria flavescens) y sus implancias en la morfología, ciclo reproductivo y dinámica poblacional del parásito. Phd Thesis. Universidad Nacional de Mar del Plata. 160 pp

Leonardi MS, Crespo EA, Raga JA, Fernández M (2009) Redescription of Antarctophthirus microchir, Trouessart \& Neumman 1888 (Anoplura: Echinophthiriidae) from the South American sea lion, Otaria flavescens, from Patagonia, Argentina. J Parasitol 95:10861092

Leonardi MS, Crespo EA, Raga JA, Fernández M (2012a) Scanning electron microscopy of Antarctophthirus microchir (Phthiraptera: Anoplura: Echinophthiriidae): studying morphological adaptations to aquatic life. Micrones 43:929-936

Leonardi MS, Crespo EA, Vales DG, Feijoo M, Raga JA, Aznar FJ (2012b) Life begins when the sea lion is ashore: Microhabitat use by a louse living on a diving mammal host. B Entomol Res 102: 444-452

Leonardi MS, Crespo EA, Raga JA, Aznar FJ (2013) Lousy mums: patterns of vertical transmission of an amphibious louse. Parasitol Res 112:3315-3323

Mehlhorn B, Mehlhorn H, Plötz J (2002) Light and scanning electron microscopical study on Antarctophthirus ogmorhini lice from the Antarctic seal Leptonychotes weddelli. Parasitol Res 88:651-660

Murray MD, Nicholls DG (1965) Studies on the ectoparasites of seals and penguins. I. The ecology of the louse Lepidophthirus macrorhini Enderlein on the southern elephant seal, Mirounga leonina (L.). Aust J Zool 13:437-454

Murray MD, Smith MSR, Soucek Z (1965) Studies on the ectoparasites of seals and penguins. II. The ecology of the louse Antarctophthirus ogmorhini Enderlein on the Weddell seal, Leptonychotes weddelli Lesson. Aust J Zool 13:761-771

Powell RA, Proulx G (2003) Trapping and marking terrestrial mammals for research: Integrating ethics, performance criteria, techniques, and common sense. ILAR J 44:259-276

Rand RW (1950) Branding in field-work on seals. J Wildl Manage 14: 128-132

Reiczigel J, Rózsa L (2005) Quantitative Parasitology 3.0. Budapest. In: D.b.t. (ed)

Rózsa L, Reiczigel J, Majoros G (2000) Quantifying parasites in samples of hosts. J Parasitol 86:228-232

Stirling I (1966) A technique for handling live seals. J Mammal 47:543544

Zar JH (1994) Biostatistical analysis. Prentice- Hall, New Jersey 